\title{
Heat Pump Design Using Peltier Element FOR TEMPERATURE CONTROL OF THE FLOW CELL
}

\author{
Abinav Pathak ${ }^{1}$ and Vikas Goel ${ }^{2}$ \\ ${ }^{1}$ Centre for Development of Advanced Computing, Mohali, Punjab, India \\ labinavpathak@gmail.com \\ ${ }^{2}$ Centre for Development of Advanced Computing, Mohali, Punjab, India \\ Vikaskgol@gmail.com
}

\begin{abstract}
In biochemistry analyzer the temperature play crucial role as many of the health parameters are tested at precise temperature. In automated bio-chemistry analyzer, precise temperature control is achieved by using the peltier device as heat pump and PID control action. The temperature is measured at the flow cell using the LM-35 temperature sensor and set point temperature is set by using the PWM output of a microcontroller employed for the control action. In the presented work, the temperature control is achieved at an accuracy of $\pm 0.1^{0} \mathrm{C}$ by controlling the design parameters of the heat pump circuit. Further, besides controlling the temperature at desired set point, the temperature achieving rate has to made as fast as possible. This is made by using an enhanced current source by suitable designing the peltier driving circuit.
\end{abstract}

\section{KEYWORDS}

$P W M \rightarrow$ Pulse width modulation, PID $\rightarrow$ Proportional integral Differential, Peltier device, SPT $\rightarrow$ Set point temperature, Heat pump, Peltier effect, Biochemistry analyzer.

\section{INTRODUCTION}

In all thermal processes, maintain the certain temperature is the main requirement. In presented work the fast thermal response is achieved by using the peltier element. Peltier element works on the principal of Peltier Effect. It states that the passage of an electric current through the junction of two dissimilar wires can either cool or heat the junction depending on the direction of current. Heat generation or absorption rates are proportional to the magnitude of the current and also the temperature of the junction. In this presented work, Set Point Temperature is achieved by using the PWM output micro-controller followed by low pass filter. Temperature is measured at flow cell using LM-35 temperature sensor. The set point voltage so obtained as above is compared with the current temperature (CT) and an error signal is generated by using an operational amplifier circuit and sends to PID algorithm to take up the necessary action. Moreover, controlling the temperature at desired set point, the temperature achieving rate has to made as fast as possible. This is made by using an enhanced current source by suitable designing the peltier driving circuit.

\section{SYSTEM DESCRIPTION}

Proposed system comprises of various modules, these modules are explained with the help of figure 1 and detail of modules is given below:

DOI : 10.5121/ijcsea.2013.3305 


\subsection{Microcontroller unit}

The NXP P89C51RD2 is an Generic 8051 Compatible High-speed Microcontroller, having 16-bit Timer/Counters, 256 Bytes Scratch Pad RAM, 9 Interrupt Sources with 4 Priority Levels Integrated Power Monitor, ISP (In-System Programming) 64K Flash on-chip, 1792 bytes on-chip XRAM, Dual Data Pointer, Serial Peripheral Interface bus, 16-bit Program counter array, Pulse width modulation, Universal Asynchronous Receiver/Transmitter, watchdog timer.

\subsection{Pulse width modulation}

A Pulse Width Modulation (PWM) module in addition with a low pass filter circuit can produce different analogue voltages. In the proposed work, this analogue voltage is used to give set point temperature voltage. A PWM of frequency, FPWM $=1 \mathrm{KHz}$ is generated using a microcontroller Input/output port pin as shown in fig. 1. A low pass filter circuit of frequency FLP $=5 \mathrm{KHz}$, using $\mathrm{R}=1 \mathrm{~K}$ and $\mathrm{C}=1 \mu \mathrm{F}$, gives a good quality set point temperature voltage.

\subsection{Heat Pump}

A heat pump is a device that transfers heat energy from a heat source to a heat sink against a temperature gradient. Heat pumps are designed to move thermal energy opposite the direction of spontaneous heat flow. A heat pump uses some amount of external high-grade energy to accomplish the desired transfer of thermal energy from heat source to heat sink. While compressor-driven air conditioners and freezers are familiar examples of heat pumps.

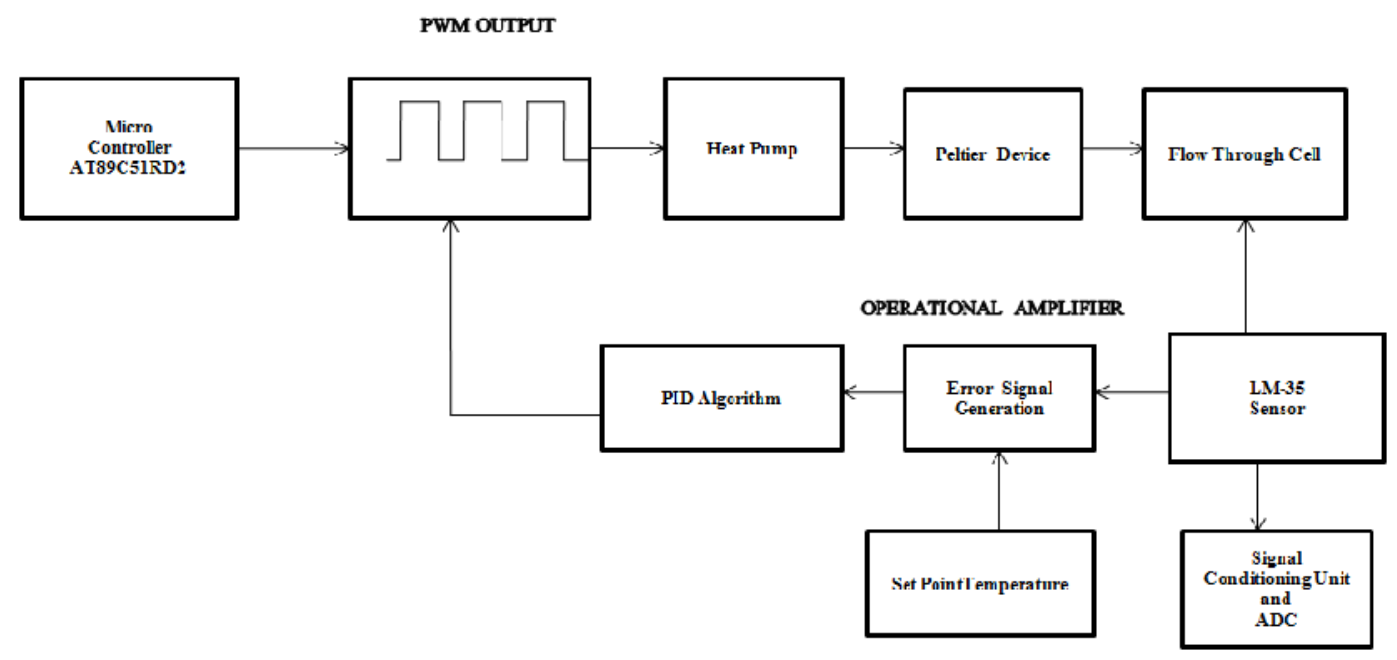

Figure 1. Block diagram of the presented work

\subsection{Principle of operation}

The basic principal of the proposed system is based on reverse of see-back effect and is known as Peltier effect. A pettier element consists of a heat conducting material along with two wires, if the flow of current is reversed through the wires, then the sides of the peltier device show the reverse temperature effect. Peltier device is shown in figure 2.

Peltier elements have following features;

It is in solid state; Need no maintenance, long service life-time. 
Peltier element has applications in deep space probes, microprocessor cooling, laser diode temperature stabilization, temperature regulated flight suits and air conditioning in submarines, Portable DC refrigerators, and automotive seat cooling/heating.

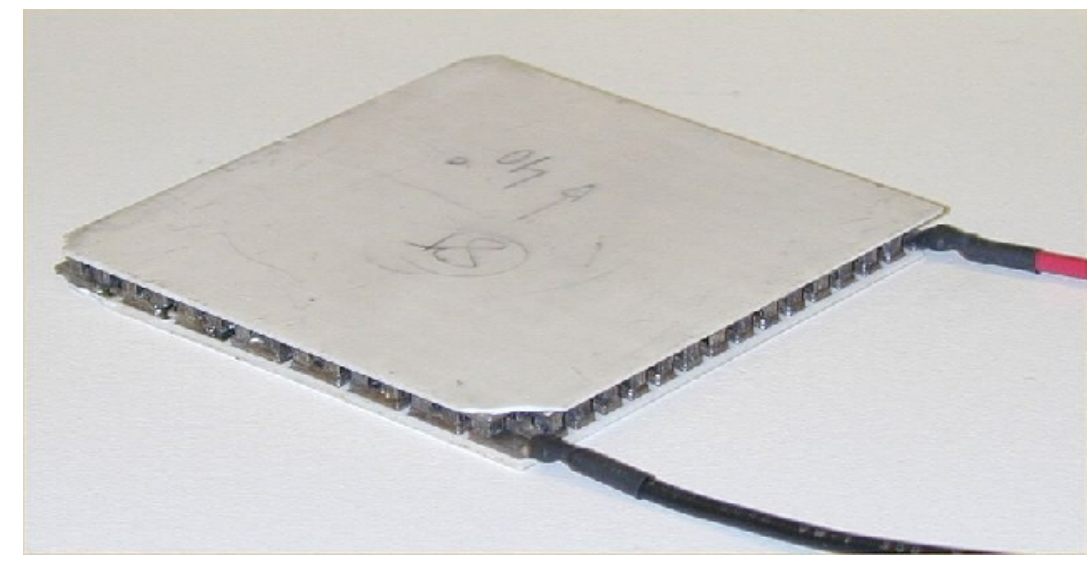

Figure 2. Peltier device

\subsection{Temperature measurement}

Temperature at flow through cell is measured using LM-35 temperature sensor. It gives $10 \mathrm{mv}$ per degree centigrade change of temperature. The analog output of LM-35 is also given to Operational amplifier to compare the same with Set point. The error signal is generated thereafter and sends to PID algorithm to take up the necessary action, shown in figure 3.

\subsection{Proportional integral derivative (PID) controller}

The proportional integral derivative controller is used to control temperature of the system. The PID control is comprised of three terms proportional, integral, and derivative. These terms are summed to calculate the output of the PID controller. Defining U ( $t)$ as the controller output, the final form of the PID algorithm is:

$\mathrm{u}(t)=\mathrm{MV}(t)=K_{p} c(t)+K_{i} \int_{0}^{t} c(\tau) d \tau+K_{d} \frac{d}{d t} c(t)$

Where, Kp: Proportional gain, a tuning parameter, Ki: Integral gain, a tuning parameter, Kd: Derivative gain, a tuning parameter. Error $=$ Set point temperature - current temperature, $\mathrm{t}=$ instantaneous time (the present), $\mathrm{T}$ : Variable of integration; takes on values from time 0 to the present $\mathrm{t}$. 


\section{FLOW DIAGRAM OF THE SYSTEM}

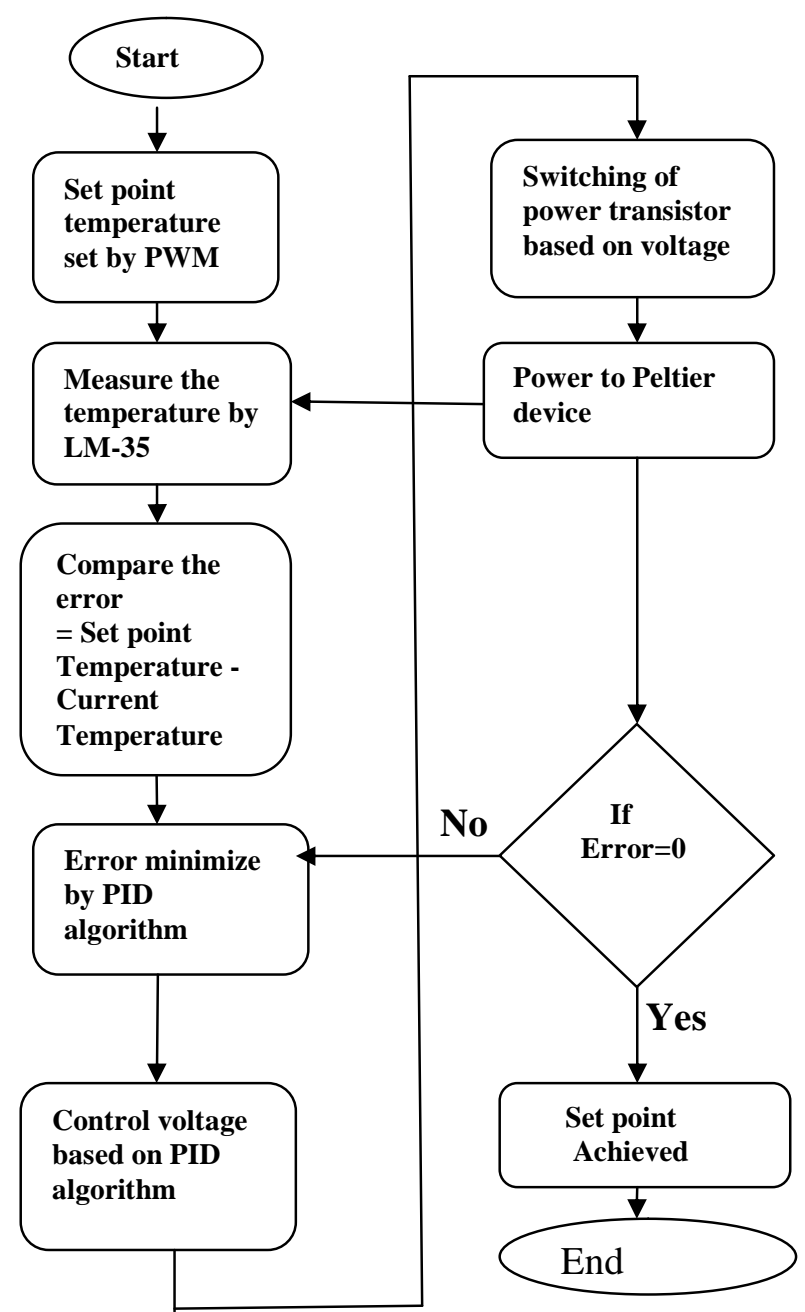

Figure 3. Flow chart of the presented work

\section{RESULTS}

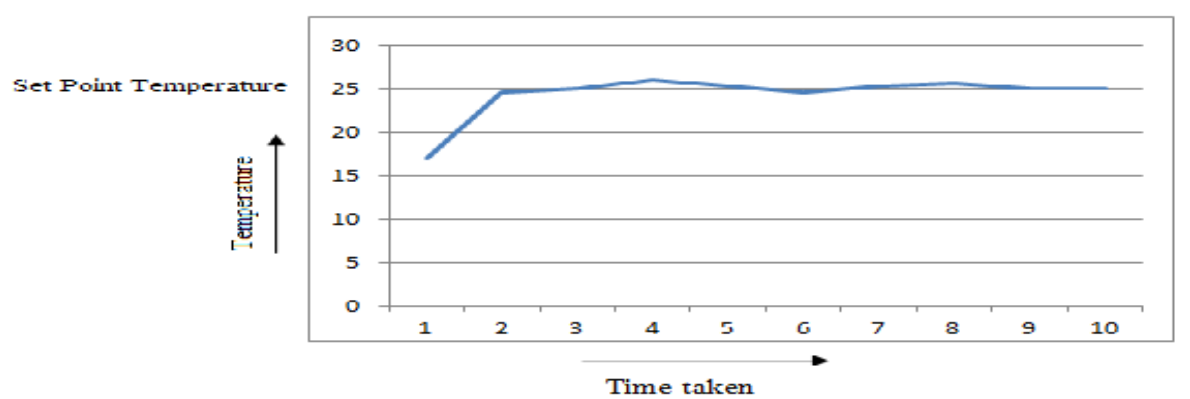

Figure4: Set point temperature for $25^{\circ} \mathrm{C}$ output 
International Journal of Computer Science, Engineering and Applications (IJCSEA) Vol.3, No.3, June 2013

Table1: shows the result of the graph drawn between temperature and time taken

\begin{tabular}{|l|l|l|l|l|}
\hline Serial no. & $\begin{array}{l}\text { Set Point } \\
\text { Temperature }\end{array}$ & $\begin{array}{l}\text { Current } \\
\text { Temperature }\end{array}$ & $\begin{array}{l}\text { Control } \\
\text { Temperature }\end{array}$ & $\begin{array}{l}\text { Time } \\
\text { Taken }\end{array}$ \\
\hline 1 & $25^{\circ} \mathrm{C}$ & $24^{\circ} \mathrm{C}$ & $25.1^{\circ} \mathrm{C}$ & $2 \mathrm{sec}$ \\
\hline 2 & $25^{\circ} \mathrm{C}$ & $30^{\circ} \mathrm{C}$ & $24.9^{\circ} \mathrm{C}$ & $3 \mathrm{sec}$ \\
\hline 3 & $25^{\circ} \mathrm{C}$ & $40^{\circ} \mathrm{C}$ & $25.2^{\circ} \mathrm{C}$ & $5 \mathrm{sec}$ \\
\hline
\end{tabular}

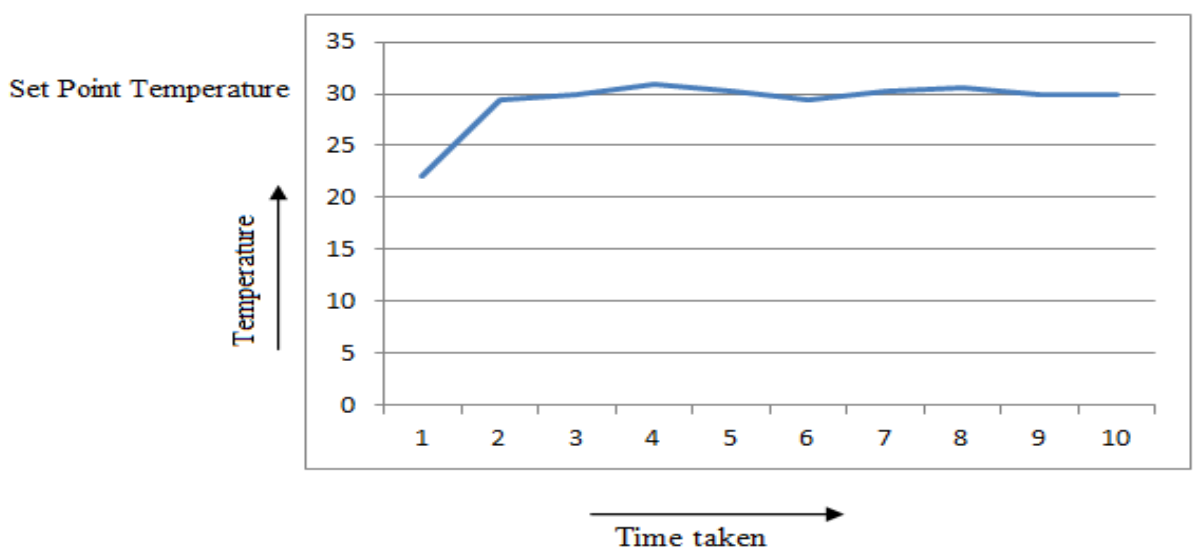

Figure 5: set point temperature for $30^{\circ} \mathrm{C}$

Table2. Illustrates the results of the temperature and time

\begin{tabular}{|l|l|l|l|l|}
\hline Serial no. & $\begin{array}{l}\text { Set Point } \\
\text { Temperature }\end{array}$ & $\begin{array}{l}\text { Current } \\
\text { Temperature }\end{array}$ & $\begin{array}{l}\text { Control } \\
\text { Temperature }\end{array}$ & Time Taken \\
\hline 1 & $30^{\circ} \mathrm{C}$ & $25^{\circ} \mathrm{C}$ & $30.01^{\circ} \mathrm{C}$ & $2 \mathrm{sec}$ \\
\hline 2 & $30^{\circ} \mathrm{C}$ & $27^{\circ} \mathrm{C}$ & $30.2^{\circ} \mathrm{C}$ & $1 \mathrm{sec}$ \\
\hline 3 & $30^{\circ} \mathrm{C}$ & $40^{\circ} \mathrm{C}$ & $29.7^{\circ} \mathrm{C}$ & $3 \mathrm{sec}$ \\
\hline
\end{tabular}

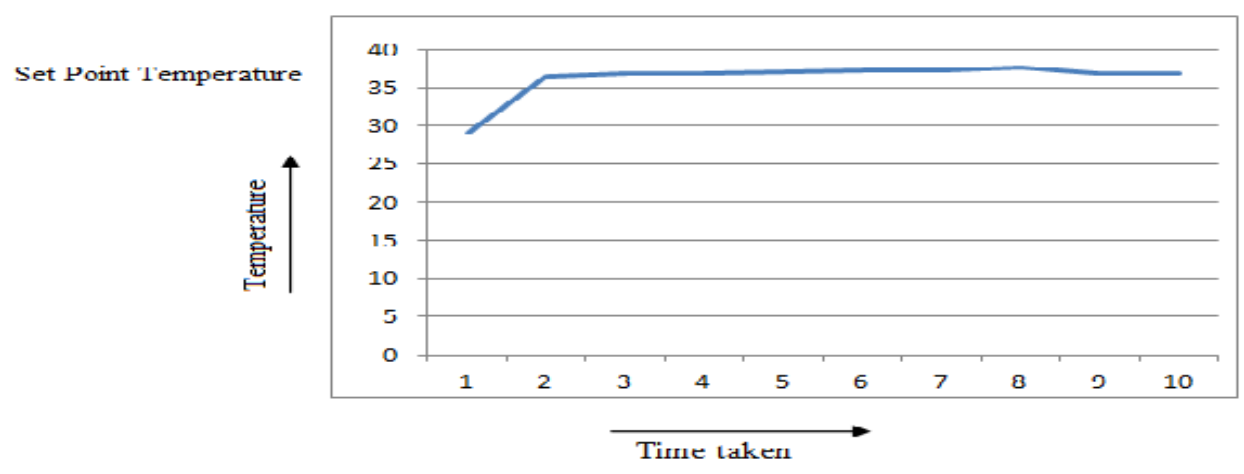

Figure 6: Figure for set point temperature at $37^{\circ} \mathrm{C}$ 
Table3. Depicts the results of the temperature and time

\begin{tabular}{|l|l|l|l|l|}
\hline Serial no. & $\begin{array}{l}\text { Set Point } \\
\text { Temperature }\end{array}$ & $\begin{array}{l}\text { Current } \\
\text { Temperature }\end{array}$ & $\begin{array}{l}\text { Control } \\
\text { Temperature }\end{array}$ & Time Taken \\
\hline 1 & $37^{\circ} \mathrm{C}$ & $25^{\circ} \mathrm{C}$ & $37.1^{\circ} \mathrm{C}$ & $5 \mathrm{sec}$ \\
\hline 2 & $37^{\circ} \mathrm{C}$ & $30^{\circ} \mathrm{C}$ & $36.9^{\circ} \mathrm{C}$ & $3 \mathrm{sec}$ \\
\hline 3 & $37^{\circ} \mathrm{C}$ & $41^{\circ} \mathrm{C}$ & $37.2^{\circ} \mathrm{C}$ & $2 \mathrm{sec}$ \\
\hline
\end{tabular}

\section{CONCLUSION}

The presented system has been tested in prototype model of fully automated bio-chemistry analyzer at C-DAC, Mohali. Attainability of the temperature within the required time limit has been achieved to appreciable limit. The main task is only to achieve the temperature within the permitted time period and it can further be improved by using peltier device of high current rating if available in the required mechanical system design size. However, there is a trade-off between the fast response and the current requirement. If fast response is desired, high current source will be used and vice versa.

\section{ACKNOWLEDGMENTS}

I would like to express my deep appreciation to Mr.Vikas Goel Senior Project manager C-DAC Mohali for inspiring and helping me in undertaking this project. I am particularly indebted to my parents for motivating me to do this work.

\section{REFERENCES}

[1] Vincent, R.J.; Waldron, W.D., "A Magnetically Coupled Stirling Engine Driven Heat Pump: Design Optimization And Operating Cost Analysis," Energy Conversion Engineering Conference, 1990. IECEC90. Proceedings of the 25th Intersociety, vol.2, no., pp.204, 210, 12-17 Aug 1990

[2] ChangLiang Liu; Hong Wang; Jinliang Ding; Chenggang Zhen, "An overview of modelling and simulation of thermal power plant," Advanced Mechatronic Systems (ICAMechS), 2011 International Conference on, vol., no., pp.86, 91, 11-13 Aug. 2011

[3] Jun-hong Yang; Xi-yan Bi, "High-precision temperature control system based on PID algorithm," Computer Application and System Modeling (ICCASM), 2010 International Conference on, vol.12, no., pp.V12-568, V12-571, 22-24 Oct. 2010

[4] Bin Feng; Gong, Guofang; Huayong Yang, "Self-tuning-parameter fuzzy PID temperature control in a large hydraulic system," Advanced Intelligent Mechatronics, 2009. AIM 2009. IEEE/ASME International Conference on, vol., no., pp.1418, 1422, 14-17 July 2009

[5] Inagaki, N.; Imai, R.; Shikida, M.; Okochi, M.; Honda, H.; Sato, K., "Temperature controlled miniaturized cell in magnetic beads handling system for bio-chemical reaction," Solid-State Sensors, Actuators and Microsystems Conference, 2009. TRANSDUCERS 2009. International, vol., no., pp.382, 385, 21-25 June 2009

[6] Ma Ya-qiang; Zhang Xiao-li; Lian Xiao-qin; Duan Zhen-gang, "Design and Implementation of the Ground Source Heat Pump Remote Monitoring System," Intelligent Computation Technology and Automation, 2009. ICICTA '09. Second International Conference on , vol.4, no., pp.62,65, 10-11 Oct. 2009

[7] Morimitsu, H.; Katsura, S., "A method to control a peltier device based on heat disturbance observer," IECON 2010 - 36th Annual Conference on IEEE Industrial Electronics Society, vol., no., pp.1222, 1227, 710 Nov. 2010.

[8] Li Nianping; Zhang Wenjie; Wang Lijie; Liu Qiuke; Hu Jinhua, "Experimental Study on Energy Efficiency of Heat-source Tower Heat Pump Units in Winter Condition," Measuring Technology and Mechatronics Automation (ICMTMA), 2011 Third International Conference on , vol.2, no., pp.135,138, 6-7 Jan. 2011

[9] Cing-Han Yang; Hsin-Wei Wang; Tsan-Huang Shih; Tun-Wen Pai, "Poster: Identification and classification of internal repeats in proteins," Computational Advances in Bio and Medical Sciences (ICCABS), 2011 IEEE 1st International Conference on , vol., no., pp.266,266, 3-5 Feb. 2011 
[8] Zhang, M.; Huan, Z., "Opportunities for the development of heat pump drying systems in South Africa," Industrial and Commercial Use of Energy Conference (ICUE), 2012 Proceedings of the 9th, vol., no., pp.1,6, 15-16 Aug. 2012

[9] Yambe, T.; Sumiyoshi, T.; Koga, C.; Shiraishi, Y.; Miura, H.; Sugita, N.; Tanaka, A.; Yoshizawa, M., "New implantable therapeutic device for the control of an atrial fibrillation attack using the Peltier element," Engineering in Medicine and Biology Society (EMBC), 2012 Annual International Conference of the IEEE, vol., no., pp.5741,5744, Aug. 28 2012-Sept. 12012

[10] Fu-hua Jen; Bao Trung Mai, "Building an autonomous line tracing car with PID algorithm," Intelligent Control and Automation (WCICA), 2012 10th World Congress on , vol., no., pp.4478,4483, 6-8 July 2012

[11] Midoro, T.; Ishida, H., "Device for determining gas source direction that uses peltier elements to collect gas samples," Sensors, 2012 IEEE , vol., no., pp.1,4, 28-31 Oct. 2012

[12] Widyotriatmo, A.; Rauzanfiqr, S.K.; Suprijanto, S., "A modified PID algorithm for dynamic control of an automatic wheelchair," Control, Systems \& Industrial Informatics (ICCSII), 2012 IEEE Conference

[13] Jun-hung Yang and Xi-Yan-Bi., "High precision temperature control system based on PID algorithm," International Conference Computer application and modelling (ICCASM), Volume no., 9, 22-24 October 2010

[14] Ma Ya-qiang; Zhang Xiao-li; Lian Xiao-qin; Duan Zhen-gang, "Design and Implementation of the Ground Source Heat Pump Remote Monitoring System," Intelligent Computation Technology and Automation, 2009. ICICTA '09. Second International Conference on, vol.4, no., pp.62, 65, 10-11 Oct. 2009

[15] Li Nianping; Zhang Wenjie; Wang Lijie; Liu Qiuke; Hu Jinhua, "Experimental Study on Energy Efficiency of Heat-source Tower Heat Pump Units in Winter Condition," Measuring Technology and Mechatronics Automation (ICMTMA), 2011 Third International Conference on , vol.2, no., pp.135,138, 6-7 Jan. 2011

[16] Fu-hua Jen; Bao Trung Mai, "Building an autonomous line tracing car with PID algorithm," Intelligent Control and Automation (WCICA), 2012 10th World Congress on, vol., no., pp.4478, 4483, 6-8 July 2012

[17] Midoro, T.; Ishida, H., "Device for determining gas source direction that uses peltier elements to collect gas samples," Sensors, 2012 IEEE, vol., no., pp.1, 4, 28-31 Oct. 2012

[18] Mingcong Deng; Yanou, A.; Tokuda, Y.; Aihui Wang, "Robust fault tolerant thermal control system design of an aluminum plate with Peltier device," Advanced Mechatronic Systems (ICAMechS), 2012 International Conference on , vol., no., pp.223,228, 18-21 Sept. 2012

[19] Melero, A.; Astrain, D.; Vian, J.G.; Aldave, L.; Albizua, J.; Costa, C., "Application of thermoelectricity and photovoltaic energy to air conditioning," Thermoelectric, 2003 Twenty-Second International Conference on - ICT , vol., no., pp.627,630, 17-21 Aug. 2003

[20] Woosung Choi; Woojong Yoo; Sangchul Won, "Development of automatic temperature control system in blast furnace," SICE-ICASE, 2006. International Joint Conference, vol., no., pp.899, 903, 18-21 Oct. 2006.

\section{AUTHORS}

Abinav Pathak is pursuing M.Tech thesis work in embedded system from CDAC Mohali. His expertise field of interest is embedded system design and control technologies.

Mr. Vikas Goel is working as Sr. Project Manager at C-DAC, Mohali. His proficiency is in design and development of embedded microcontroller based systems
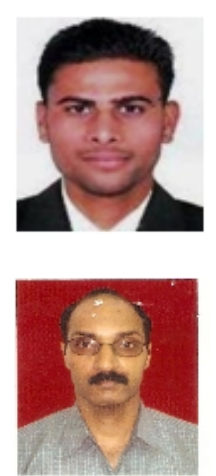